\title{
Idiosyncratic Side Effects of Hydroxyurea in Patients with Sickle Cell Anemia Samir K Ballas ${ }^{*}$, Priya Singh ${ }^{1}$, Patricia Adams-Graves ${ }^{2}$ and Cindy J Wordell ${ }^{3}$
}

${ }^{1}$ Sickle Cell Center, Cardeza Foundation, Department of Medicine, Jefferson Medical College, Thomas Jefferson University, Philadelphia, PA, USA

${ }^{2}$ Diggs-Kraus Sickle Cell Center, University of Tennessee Health Science Center, Memphis, TN, USA

${ }^{3}$ Department of Pharmacy, Thomas Jefferson University Hospital, Philadelphia, PA, USA

\begin{abstract}
Hydroxyurea was approved by the Food and Drug Administration for the treatment of adults with moderate to severe sickle cell anemia and sickle- $\beta^{0}$-thalassemia. Its major side effect is myelotoxicity, which is reversible upon discontinuation of the drug. Other side effects that have been described in animal studies but unconfirmed in humans include its teratogenic and carcinogenic potential. Additionally, hydroxyurea has idiosyncratic side effects that occur in some individuals and this may be a genetic or epigenetic phenomenon. We report three idiosyncratic side effects of hydroxyurea in four patients with sickle cell anemia (SS). Desquamating rash, decreased libido and partial complex seizures have not been previously described in patients who are hydroxyurea responders. Although these reactions are rare, they can be serious in some patients.
\end{abstract}

Keywords: Sickle cell anemia; Sickle cell disease; Hemoglobinopathy; Hydroxyurea

\section{Introduction}

Hydroxyurea (HU) was approved by the Food and Drug Administration (FDA) on February 25, 1998 to decrease the frequency of painful crises, decrease the frequency of acute chest syndrome and decrease the need for blood transfusions in adult patients with moderate to severe sickle cell anemia (SS) and sickle- $\beta^{0}$-thalassemia $\left(\mathrm{S}-\beta^{0}-\mathrm{T}\right)$. Currently it is the only FDA approved drug for patients with SS. Chemically HU is a synthetic urea analog; also referred to as hydroxycarbamide that functions as an antineoplastic agent. The mechanism by which it produces cytotoxicity and myelosuppression is unknown. However, various studies suggest that it is cell cycle specific for the $S$ phase and inhibits DNA synthesis as a ribonucleotide reductase inhibitor. Hydroxyurea induces the production of hemoglobin $(\mathrm{Hb}) \mathrm{F}$ in the majority of patients with SS who are compliant with therapy and thus prevents the formation of $\mathrm{Hb} \mathrm{S}$ polymers. The molecular mechanism in which it increases $\mathrm{Hb} \mathrm{F}$ is also unclear. Proposed mechanisms include selectively killing cells in the bone marrow, and increasing the number of early erythroid progenitors such as fetal erythroblasts that lead to production of $\mathrm{Hb} \mathrm{F}$ reticulocytes. It also reduces reticulocytes and circulating inflammatory cells such as monocytes and neutrophils

\begin{tabular}{|l|}
\hline Toxic \\
\hline Myelosuppression \\
\hline Leukopenia/Neutropenia \\
\hline Thrombocytopenia \\
\hline Anemia \\
\hline Megaloblastic Erythropoiesis \\
\hline Idiosyncratic \\
\hline Nausea, Vomiting \\
\hline Stomatitis, Anorexia, Diarrhea, \\
\hline Constipation \\
\hline Skin rash, Erythema \\
\hline Hair Loss \\
\hline Effects reported in animals \\
\hline Carcinogenesis \\
\hline Teratogenesis \\
\hline Long Term effects \\
\hline Unknown \\
\hline
\end{tabular}

Table 1: Side Effects of Hydroxyurea. which may be clinically important. It appears that patients whose high neutrophil and reticulocyte counts decrease significantly after HU therapy have a higher increase in $\mathrm{Hb} F$ levels [1-4].

Additionally in patients with SS, known pharmacologic effects include increasing the water content of RBCs, increasing deformability of sickled cells, and altering the adhesion of RBCs to endothelium, all of which can alleviate pain crises and decrease morbidity and mortality in patients with SS [1,2,5-8].

The common side effects of hydroxyurea are listed in (Table 1) Toxic effects are dose and time dependent and can be prevented by careful monitoring and surveillance. Side effects are generally reversible with cessation or decrease of the drug dose. Hydroxyurea is myelosuppressive and leukopenia is the most common manifestation followed by thrombocytopenia and anemia. Macrocytosis is common and may mask folic acid deficiency, so folic acid supplementation is recommended during treatment with HU. It is genotoxic and tumorigenic in animals [9].

There are case reports of leukemia in patients treated with chronic HU for myeloproliferative disorders. Whether HU leads to leukemogenesis or this is a natural progression of the underlying myeloproliferative disorder is unclear. It has also been reported to cause skin cancer, but long term data on its carcinogenic potential is not yet available [9].

Non-hematologic events reported with HU treatment include hair loss, fever, weight gain, parvovirus B-19 infection, gastrointestinal symptoms (stomatitis, anorexia, nausea, vomiting, diarrhea, and constipation), and dermatological reactions such as

*Corresponding author: Samir K. Ballas, Cardeza Foundation, 1015 Walnut Street, Philadelphia PA 19107, USA, Tel: 856-745-6380; Fax: 856-795-0809; E-mail: samir.ballas@jefferson.edu

Received August 20, 2013; Accepted October 07, 2013; Published October 12 2013

Citation: Ballas SK, Singh P, Adams-Graves P, Wordell CJ, (2013) Idiosyncratic Side Effects of Hydroxyurea in Patients with Sickle Cell Anemia. J Blood Disorders Transf 4: 162. doi: 10.4172/2155-9864.1000162

Copyright: ( $) 2013$ Ballas SK, et al. This is an open-access article distributed under the terms of the Creative Commons Attribution License, which permits unrestricted use, distribution, and reproduction in any medium, provided the original author and source are credited. 
maculopapular rash, skin ulceration, dermatomyositis-like skin changes, peripheral erythema, hyperpigmentation, longitudinal and horizontal, melanonychia, and facial erythema. Large doses may produce moderate drowsiness. Hydroxyurea occasionally may cause temporary impairment of renal tubular function accompanied by elevations in serum uric acid, BUN, and creatinine levels. Elevation of hepatic enzymes has also been reported. There are also rare reports of association of $\mathrm{HU}$ with pulmonary fibrosis [9]

We describe three idiosyncratic effects of $\mathrm{HU}$ in patients with SS that have not been previously reported.

\section{Methods}

Treatment with $\mathrm{HU}$ was as described by the multicenter study of $\mathrm{HU}$ in SS (MSH) [8]. Specifically patients were started on $10 \mathrm{mg} / \mathrm{kg}$ of $\mathrm{HU}$ and followed regularly in the outpatient clinic. They were monitored periodically by checking blood counts and biochemical parameters by routine laboratory methods. Complete blood counts, reticulocyte count, lactate dehydrogenase (LDH), alanine aminotransferase (ALT), aspartate aminotransferase (AST) and serum creatinine were determined twice per month initially and less often later to rule out possible hepatic or renal side effects. Hb F levels were checked every two months. The dose was adjusted every 4-6 weeks as needed until the $\mathrm{MCV}$ and $\mathrm{Hb} \mathrm{F}$ levels increased in the presence of non-toxic values of blood counts and the absences of hepatic, renal and severe allergic or idiosyncratic side effects (Table 1). Toxic values included white blood cell count $<2000 / \mathrm{uL}$, platelet count $<80,000 / \mathrm{uL}$ and decrease in $\mathrm{Hb}$ level by $2 \mathrm{~g} / \mathrm{dL}$ compared to baseline values.

All patients described met the inclusion criterion of more than three vaso-occlusive painful crises per year that required treatment in a medical facility as defined by MSH. They were followed in our center for many years ranging from 5 to over 20 years.

\section{Cutaneous side effect: Desquamating pruritic rash}

A 45 year-old man with SS has been taking $500 \mathrm{mg}$ of the brand formulation of HU [Hydrea, Droxia (Bristol-Meyers Squibb Company, Princeton, NJ)] for years with a salutary response. He was one of the patients who enrolled in MSH and has been followed in our center for over 20 years. Major complications of his disease included avascular necrosis of both shoulders and pneumonia. After treatment with $\mathrm{HU}$ his $\mathrm{Hb} \mathrm{F}$ levels increased from $<2.0 \%$ to $4.1 \%$, $\mathrm{Hb}$ level increased from

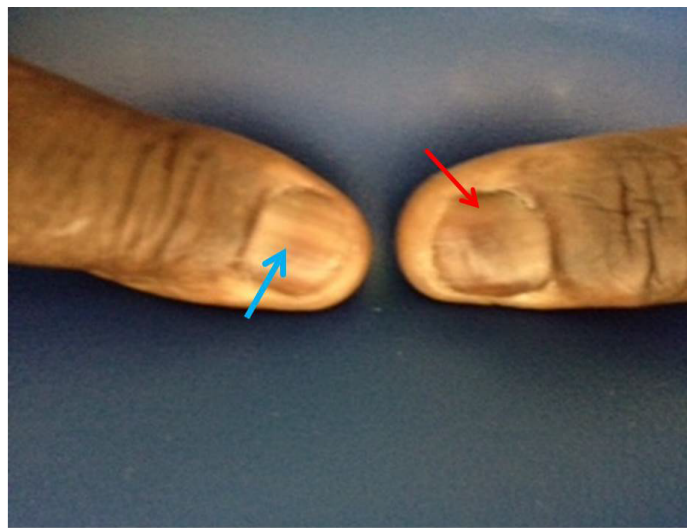

Figure 1: Fingernails of a 38-year-old man with sickle cell anemia and hydroxyurea-induced melanonychia characterized by longitudinal (blue arrow) and diffuse (red arrow) bands.
8.4 to $10.1 \mathrm{~g} / \mathrm{dL}$ the MCV increased from 77 to $98 \mathrm{fl}$ and white blood cell (WBC) count decreased from 14,800 to 8,500 per uL. Because of a change in insurance coverage, he was switched to a generic form of HU. Approximately one week later he developed severe itching, scaling and peeling of the skin over his arms, legs and trunk. These signs and symptoms disappeared one week after discontinuing the drug and did not recur after restarting a different generic formulation of $\mathrm{HU}$.

From this presentation it appears the dermatologic effects described are not due to the hydroxyurea itself, but to an excipient of the generic formulation of hydroxyurea. An excipient is an inert substance or inactive ingredient such as starch or gum Arabica that serves as a filler, binder and/or coloring agent for a drug. Excipients used in Hydrea include citric acid, colorant (FD\&C yellow \#10, FD\&C blue \#1, FD\&C red \#40 and FD\&C red \#28), magnesium stearate, sodium phosphate, gelatin, lactose, and titanium dioxide [9].

Acute mucocutaneous toxicity has been reported in patients receiving $\mathrm{HU}$ at dosages several times the therapeutic dose. Soreness, violet erythema, edema on palms and soles followed by scaling of hands and feet, severe generalized hyperpigmentation of the skin and stomatitis have been observed, but our patient did not receive an overdose. Some patients with myeloproliferative disorders who were treated with HU developed cutaneous vasculitic toxicities, including vasculitic ulcerations and gangrene. These events occurred most often in patients who were currently receiving interferon or had a history of interferon therapy. There is one report of a cutaneous rash in a child, but details of this have not been described [10]. In patients with myeloproliferative disorders severe cutaneous and mucosal reactions have been reported and include skin atrophy with associated telangiectasias, dryness, hyperpigmentation of nails, skin, mucosal, stomatitis, glossitis, actinic keratosis, alopecia, melanonychia, squamous cell carcinomas of sun exposed areas, keratoacanthomas, acral erythema, dermatomyositislike changes of hands and ulcers of skin and mucous membranes [11-13]. To our knowledge, the rash that we observed has not been described in sickle cell patients receiving HU.

Additionally, we observed longitudinal melanonychia in patients on HU therapy with SS. Hydroxyurea has been associated with several nail changes both in children and adults both in the non-sickle and the sickle cell population [14-17]. Our patient who is a 38 year-old man with SS on HU therapy developed longitudinal melanonychia in all 20 digits of his hands and feet 16 weeks after therapy with HU. On physical examinations, there were hyperpigmented lines on digits as noted in Figure 1. His WBC count decreased from 15,500 to 7,400/ $\mathrm{uL}$, the MCV increased from 88 to $118 \mathrm{fl}$ and $\mathrm{Hb}$ level increased from 7.1 to $9.4 \mathrm{~g} / \mathrm{dL}$ at the time of nail changes. Accordingly melanonychia may be a surrogate marker of adherence to HU therapy. The differential diagnosis for longitudinal melanonychia includes melanoma, benign melanocytic nevus, drug induced nail hyperpigmentation, ethnic type nail hyperpigmentation and trauma. The pathophysiology of HU induced melanonychia is unclear and it has been suggested that this may be direct toxic effect of $\mathrm{HU}$, genetic predisposition to nail changes, photosensitization or local stimulation of melanocytes [14,15].

Longitudinal melanonychia has been reported in patients taking $\mathrm{HU}$ for myeloproliferative disorders, and is underreported in the sickle cell population and thalassemia [18-21]. Moreover, the patient described above demonstrates that melanonychia seems to be a surrogate marker of response to $\mathrm{HU}$.

\section{Sexual dysfunction: Decreased libido}

Two patients experienced decreased libido attributed to HU. A 24 
year-old man with SS and cholecystectomy due to cholelithiasis had a good response to $\mathrm{HU}$ (1000 mg daily) noted decreased libido, which returned to normal after discontinuing the drug. After treatment with $\mathrm{HU}$ his $\mathrm{Hb} \mathrm{F}$ levels increased from 4.0 to $16.0 \%$, Hb level increased from 8.2 to $10.3 \mathrm{~g} / \mathrm{dL}$ the MCV increased from 75 to $88 \mathrm{fl}$ and WBC count decreased from 18,700 to 11,400 per uL. He refused to retry HU therapy due to this effect. A second patient also noted decreased libido after taking HU. This 27 year-old woman with SS with a history of severe jaundice, mitral valve prolapse, and acute chest syndrome was started on hydroxyurea $1000 \mathrm{mg}$ daily. Her $\mathrm{Hb} \mathrm{F}$ level increased from 2.0 to 9.0\% with improvement in jaundice, but she noted an accompanying decreased libido. After discontinuing hydroxyurea her libido returned to pretreatment status in 1-2 months. A second trial of $\mathrm{HU}$ resulted in the same decrease in libido and she discontinued the drug since then.

Sexual dysfunction in these patients may be similar to that associated with antidepressants. Antidepressants have well established sexual side effects including changes in libido, impotence, priapism, and ejaculatory dysfunction. There are also reports of reversible azospermia associated with hydroxyurea [22,23].

\section{Neurological side effect: Seizure}

A 26 year-old man with SS complicated by severe jaundice, acute chest syndrome, and recurrent acute painful episodes had an excellent response to $\mathrm{HU}$ at $1500 \mathrm{mg}$ daily. After treatment with $\mathrm{HU}$ his $\mathrm{Hb} \mathrm{F}$ levels increased from $6.0 \%$ to $20 \%$, Hb level increased from 8.0 to $10.7 \mathrm{~g} / \mathrm{dL}$ the MCV increased from 90 to $118 \mathrm{fl}$ and WBC count decreased from 16,800 to 9,150 per uL. His jaundice resolved, he was free of further pain crises and acute chest syndrome and his $\mathrm{Hb} \mathrm{F}$ level reached a maximum of $20 \%$. About one year after initiating $\mathrm{HU}$ he experienced a sudden change in behavior, attacking his girlfriend and friends at a picnic. His violent and combative behavior lasted a few hours until he was restrained with handcuffs by the police. $\mathrm{He}$ had no recollection of this incident after being taken to the emergency department. Neurological evaluation including an MRI/MRA of the brain was normal. His final diagnosis was partial complex seizures with hydroxyurea as the most likely inciting agent. He was taken off $\mathrm{HU}$ and within 6 months developed an acute pain crisis followed by acute chest syndrome. At his request, he was restarted on a lower dose of HU (100 $\mathrm{mg}$ /day) with careful monitoring. So far he is doing fine.

There are no reports of seizure activity attributed to HU therapy that we are aware of. Neurological disturbances have occurred extremely rarely and were limited to headache, dizziness, disorientation, hallucinations, and convulsions.

\section{Conclusion}

Hydroxyurea may be associated with certain idiosyncratic side effects in some patients. We reported an unusual desquamating, pruritic rash, decreased libido and a partial complex seizure in 4 patients with sickle cell anemia during treatment with hydroxyurea. Additionally, longitudinal melanonychia was noted in 2 patients on $\mathrm{HU}$ for sickle cell disease in our practice. In our experience of treating over 60 patients with hydroxyurea, these side effects are rare. The incidences of the described dermatologic and neurologic side effects were $1.5 \%$ each and sexual dysfunction and longitudinal melanonychia were $3.0 \%$ in our patient population on HU. Moreover, none of these complications were described in the 150 patients taking $\mathrm{HU}$ in MSH. Combining our 60 patients with the 150 patients in MSH to a total of 210 patients, the incidences of each idiosyncratic complication of $\mathrm{HU}$ described above becomes $\leq 1 \%$. Although these side effects were reversible with cessation of HU therapy, they can be serious and clinical judgment and patient preference is important in clinical decisions in discontinuing hydroxyurea that may be controlling the underlying sickle cell disease.

\section{References}

1. Steinberg MH (1999) Management of sickle cell disease. N Engl J Med 340 : 1021-1030.

2. Hankins JS, Ware RE, Rogers ZR, Wynn LW, Lane PA, et al. (2005) Long-term hydroxyurea therapy for infants with sickle cell anemia: the HUSOFT extension study. Blood 106: 2269-2275.

3. Steinberg MH, Barton F, Castro O, Pegelow CH, Ballas SK, et al. (2003) Effect of hydroxyurea on mortality and morbidity in adult sickle cell anemia: risks and benefits up to 9 years of treatment. JAMA 289: 1645-1651.

4. Steinberg MH, Nagel RL, Brugnara C (1997) Cellular effects of hydroxyurea in $\mathrm{Hb}$ SC disease. Br J Haematol 98: 838-844.

5. Steinberg MH, McCarthy WF, Castro O, Ballas SK, Armstrong FD, et al. (2010) The risks and benefits of long-term use of hydroxyurea in sickle cell anemia: A 17.5 year follow-up. Am J Hematol 85: 403-408.

6. Ballas SK, Marcolina MJ, Dover GJ, Barton FB (1999) Erythropoietic activity in patients with sickle cell anaemia before and after treatment with hydroxyurea. Br J Haematol 105: 491-496.

7. Ballas SK, Dover GJ, Charache S (1989) Effect of hydroxyurea on the rheological properties of sickle erythrocytes in vivo. Am J Hematol 32: 104-111.

8. Charache S, Terrin ML, Moore RD, Dover GJ, Barton FB, et al. (1995) Effect of hydroxyurea on the frequency of painful crises in sickle cell anemia. Investigators of the Multicenter Study of Hydroxyurea in Sickle Cell Anemia. N Engl J Med 332: 1317-1322.

9. Package insert (2011) Hydroxyurea, Bristol Myers Squibb Company: Princeton NJ.

10. de Montalembert M, Bégué P, Bernaudin F, Thuret I, Bachir D, et al. (1999) Preliminary report of a toxicity study of hydroxyurea in sickle cell disease. French Study Group on Sickle Cell Disease. Arch Dis Child 81: 437-439.

11. Chaine B, Neonato MG, Girot R, Aractingi S (2001) Cutaneous adverse reactions to hydroxyurea in patients with sickle cell disease. Arch Dermatol 137: $467-470$.

12. Salmon-Ehr V, Leborgne G, Vilque JP, Potron G, Bernard P (2000) [Secondary cutaneous effects of hydroxyurea: prospective study of 26 patients from a dermatologic consultation]. Rev Med Interne 21: 30-34

13. Vassallo C, Passamonti F, Merante S, Ardigò M, Nolli G, et al. (2001) Mucocutaneous changes during long-term therapy with hydroxyurea in chronic myeloid leukaemia. Clin Exp Dermatol 26: 141-148.

14. UtaÅŸ S, Kulluk P (2010) A case of hydroxyurea-induced longitudinal melanonychia. Int J Dermatol 49: 469-470.

15. Aste N, Fumo G, Contu F, Aste N, Biggio P (2002) Nail pigmentation caused by hydroxyurea: report of 9 cases. J Am Acad Dermatol 47: 146-147.

16. Adams-Graves P, Heltsley C, Deitcher S (1996) Hydroxyurea in sickle cell disease. N Engl J Med 334: 333-334.

17. O'branski EE, Ware RE, Prose NS, Kinney TR (2001) Skin and nail change in children with sickle cell anemia receiving hydroxyurea therapy. J Am Acad Dermatol 44: 859-861

18. Las Heras G, Juncà Piera J (1998) Nail changes after chemotherapy Haematologica 83: 748.

19. Zargari O, Kimyai-Asadi A, Jafroodi M (2004) Cutaneous adverse reactions to hydroxyurea in patients with intermediate thalassemia. Pediatr Dermatol 21 $633-635$.

20. Issaivanan M, Mitu PS, Manisha C, Praveen K (2004) Cutaneous manifestations of hydroxyurea therapy in childhood: case report and review. Pediatr Dermato 21: $124-127$

21. Ranta D, Bonmati C (2009) Images in clinical medicine. Acquired melanonychia N Engl J Med 361: 1188

22. Masood J, Hafeez A, Hughes A, Barua JM (2007) Hydroxyurea therapy: a rare cause of reversible azoospermia. Int Urol Nephrol 39: 905-907.

23. Grigg A (2007) Effect of hydroxyurea on sperm count, motility and morphology in adult men with sickle cell or myeloproliferative disease. Intern Med $\mathrm{J} 37$ : 190-192. 